\title{
Unilateral diffuse plantar keratoderma: An example of cutaneous mosaicism?
}

\section{Unilateral diffüze plantar keratoderma: Kutane mozaisizmin bir örneği olabilir mi?}

\author{
*Gökhan Okan ${ }^{1}$, Burak Tekin², Nesimi Büyükbabani ${ }^{3}$, Ayşe Deniz Yücelten ${ }^{2}$ \\ ${ }^{1}$ Department of Dermatology, Kemerburgaz University School of Medicine \\ ${ }^{2}$ Department of Dermatology, Marmara University School of Medicine \\ ${ }^{3}$ Department of Pathology, İstanbul University School of Medicine \\ Corresponding author: Dr. Gökhan Okan, Department of Dermatology, Kemerburgaz University School \\ of Medicine, TR-34218 İstanbul. \\ E-mail: gokhanokan8@hotmail.com \\ Received/Accepted: September 20, 2014/October 27, 2014 \\ Conflicts of interest: There is no conflict of interest.
}

Palmoplantar keratodermas (PPKs) are a heterogeneous group of disorders characterized by thickening of the epidermis of the palms and soles. Clinically, three forms can be seen: Diffuse, focal, and punctate. Although usually manifesting on bilateral palms and soles, a unilateral presentation has been reported $^{1-3}$.

A 22-year-old female, product of a nonconsanguineous marriage, presented with diffuse thickening and yellowish discoloration of her right sole since childhood (Figure 1). The patient denied having affected relatives. She complained of tenderness and discomfort upon walking. Physical examination revealed a thick yellow-colored plaque with superficial fissures covering the entire surface of the sole, more prominent on the anterior aspect and heel. There were no similar lesions on other parts of the body. There was no involvement in the right and left hand, or left sole. Histopathologic examination of the skin biopsy specimen demonstrated marked hyperkeratosis. According to clinical symptoms and history, the patient was diagnosed with unilateral diffuse plantar keratoderma. She was treated with topical urea and salicylic acid combination but the lesions did not heal completely and recurrence was observed shortly after cessation of the therapy. The patient refused to receive systemic acitretin due to its side effects. Because of its cost, the patient did also not want to have ablative laser treatment. We have been following up the patient regularly.

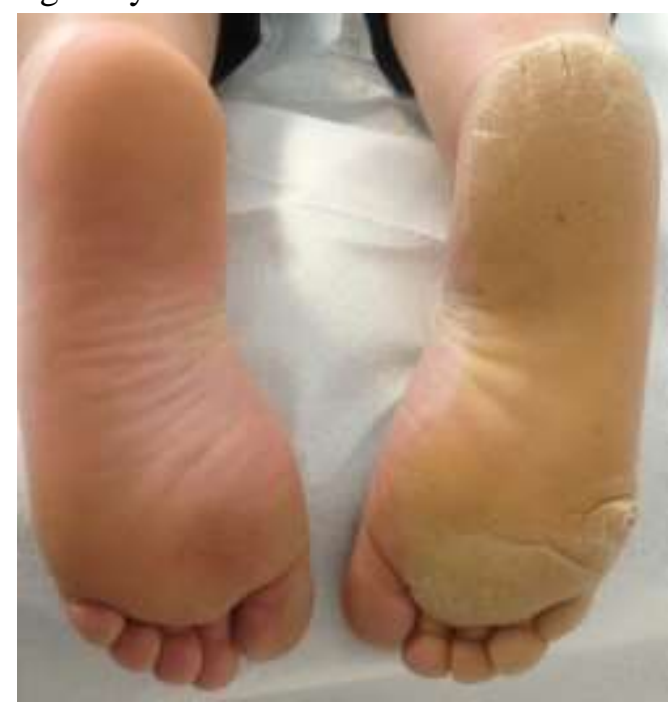

Figure 1: Well-demarcated hyperkeratotic plaque with fissures covering the right sole of the patient. Note that the left sole is spared.

The exact etiology of PPKs are not known. Autosomal recessive, autosomal dominant, $\mathrm{X}$-linked, and acquired forms have been described ${ }^{4}$. Generally, the involvement is bilateral. We propose that genetic mosaicism accounts for the unilateral nature of this patient's lesions. It remains 
unknown whether or not this patient's gametes are affected. Genetic mosaicism for a keratin 16 mutation has previously been demonstrated on a molecular level in a patient with unilateral palmoplantar hyperkeratotic lesions, representing a type 1 mosaicism of pachyonychia congenita, an autosomal dominantly inherited rare syndromic form of $\mathrm{PPK}^{3}$. Thus, it can be speculated that the rare examples of unilateral PPKs and isolated palmar or plantar variants (such as our case) without systemic manifestations represent type 1 mosaic conditions of well-known forms of PPK, although this can't always be proven on a genetic basis due to the diversity of responsible genes. Furthermore, from a nosological viewpoint, unilateral PPK may also be designated as an epidermal nevus with palmoplantar localization ${ }^{5}$.

In conclusion; the term mosaicism can help to figure out the more localized presentations of skin diseases that are commonly seen in a bilateral form, such as palmoplantar keratoderma.

\section{REFERENCES}

1. Sharma S, Barman KD, Garg VK, Jain S. Unilateral linear punctate palmoplantar keratoderma. Indian J Dermatol Venereol Leprol 2012; 78: 85-8.

2. Biyik Ozkaya D, Tas B, Su O, Unal Cakiter A, Tosuner Z, Demirkesen C. Unilateral linear punctate palmar keratoderma. J Dermatol 2014; 41: 449-50.

3. Terrinoni A, Puddu P, Didona B, De Laurenzi V, Candi E, Smith FJ. A mutation in the VI domain of $\mathrm{K} 16$ is responsible for unilateral palmoplantar verrucous nevus. J Invest Dermatol 2000; 114: 113640.

4. Braun FM. Hereditary palmoplantar keratodermas. J Dtsch Dermatol Ges 2009; 7: 971-84.

5. Moss C. Mosaicism and Linear Lesions. In: Bolognia JL, Jorizzo JL, Schaffer JV, editors. Dermatology. 3rd ed. China: Elsevier 2012; 943-62. 